\title{
The Fatigue Response of Environmentally Degraded Adhesively Bonded Aluminium
}

\section{Structures}

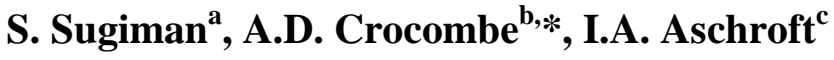 \\ a Department of Mechanical Engineering, Faculty of Engineering, University of Mataram, Mataram, West \\ Nusa Tenggara, 83125, Indonesia. \\ ${ }^{\mathrm{b}}$ Division of Mechanical, Medical and Aerospace Engineering, Faculty of Engineering and Physical \\ Sciences, University of Surrey, Guildford, Surrey, GU2 7XH, UK. \\ ${ }^{\mathrm{c}}$ Wolfson School of Mechanical and Manufacturing Engineering, Loughborough University, Loughborough, \\ UK.
}

\begin{abstract}
Experimental studies have been undertaken investigating the effect of moisture on the fatigue response of adhesively bonded monolithic single lap joints and laminated doublers loaded in bending, both made of the same materials. The joints were aged in deionised water at a temperature of $50^{\circ} \mathrm{C}$ for up to 2 years exposure. The backface strain technique was employed to monitor damage initiation and propagation in the joints. The test results show that the fatigue life degraded with increasing moisture content and tended to level off when approaching saturation. The failure surfaces were cohesive in the adhesive. Numerical fatigue modelling has been undertaken to predict the fatigue response of these joints utilising a strain-based fatigue damage law integrated with a bilinear tractionseparation cohesive zone model. The residual stresses due to thermal and swelling strain were included in the model. Good agreement was found between the predicted fatigue response and the experimental results.
\end{abstract}

Keywords: epoxy/epoxides, aluminium and alloys, finite element stress analysis, fatigue, environmental issues.

* Corresponding author. Phone: +44 1483 689194, E-mail address: a.crocombe@surrey.ac.uk 


\section{Introduction}

In service, adhesively bonded joints are often subjected to fatigue loading. Under such loading, the joints will fail at stress levels much lower than those under monotonic loading. The mechanical properties of the joints will generally be adversely affected during operation in an aqueous environment [1]. This then becomes an extensive research field, experimentally and numerically, as many factors influence the fatigue performance of the joint.

Many studies of the effect of surface treatment on aluminium-adhesive joint fatigue performance have been reported in the literature including chromic acid etching (CAE), phosphoric acid anodising (PAA), phosphoric acid anodising and priming (PAAP), grit blasted and degreasing (GBD) and silane treatments [2-6]. In a dry condition, the fatigue failure surfaces of these treatments are generally cohesive in the adhesive, however in wet conditions, the PAA and PAAP surface treatments generally continue to fail cohesively, while failure with other surface treatments are often more interfacial.

Some environmental fatigue crack growth studies have been performed by conditioning the specimen during the test [2-5]. Based on a fracture mechanics approach (Paris law), Liechti et al. [7] found that in air and in salt water, raising the temperature reduced the threshold energy release rate and this decrease was more in salt water than in air. Ferreira et al. [8] studied composite bonded joints and showed that degradation at a high immersion temperature $\left(70^{\circ} \mathrm{C}\right)$ was much more than at a temperature of $40^{\circ} \mathrm{C}$. This is due to the increase of moisture diffusion as well as temperature effects. 
Experimental studies on the fatigue life of aged adhesively bonded joints tend to be time consuming, therefore, developing a predictive response using numerical modelling is worthwhile. Two approaches to this modelling are a cycle-by-cycle approach [9-11] and characterising the cyclic loading by the maximum fatigue load [12-15]. In high cycle fatigue, a cycle-by-cycle approach can be very demanding in term of computational cost. Therefore, considering only the maximum fatigue load is often more practical. Recently, Khoramishad et al. [14] used a maximum strain-based fatigue model in conjunction with a maximum fatigue load approach to predict the fatigue life of unaged single lap joints and laminated doublers loaded in bending using a bilinear traction-separation cohesive zone model. This model was further generalised to accommodate the effect of load ratio on the fatigue life and was successfully applied to predict the fatigue response of adhesively bonded joints with different adhesive systems [15]. In those works $[14,15]$, the traction was degraded, however the cohesive stiffness remained constant over the entire life. This seems counter-intuitive as one might expect the stiffness of the material to degrade as the damage accumulated. Furthermore, the critical traction value was high compared with the cohesive strength of the bulk adhesive (although some literature report $[16,17]$ that the limiting traction can be treated purely as a penalty parameter). This resulted in unrealistic stress states in the adhesive layer.

The backface strain technique was initially used to monitor crack initiation and propagation in welded structures [18]. This was then extended to adhesively bonded joints to detect damage initiation [19]. Further study showed that the peak strain often occurred when the damage has reached the detecting gauge position [20]. Experimental evidence combining microscopy images of partially fatigued joints with backface strain measurements showed that the damage initiation process occupied up to $50 \%$ of total 
fatigue life [21]. However the proportion of initiation and propagation phases in the fatigue life of single lap joints has been shown to depend on overlap length, applied stress level and fillet shape [22]. Further, Solana et al. [13] and Khoramishad et al. [14, 15] predicted the backface strain response using finite element modelling (FEM) of the bonded joint and although they used a different approach to model adhesive damage, good agreement was found between FEM and experimental results in both cases.

This paper presents experimental and numerical studies of the fatigue response of monolithic single lap joints (MSLJ) and laminated doublers loaded in bending (LDB) aged in deionised water at temperature of $50^{\circ} \mathrm{C}$ for up to 2 years. Numerical modelling used a maximum strain-based fatigue damage model integrated with the cohesive zone model to predict the fatigue response of the aged joints and included residual stresses due to thermal and swelling strains. The backface strain technique was used to monitor the fatigue damage evolution in the adhesive layer and thus to provide a means of calibrating the parameters in the strain-based fatigue damage law. Further evidence of experimental damage was obtained using in-situ video-microscopy.

\section{Experimental method}

\subsection{MSLJ manufacturing}

The single lap joint substrates were $\mathrm{Al}$ 2024-T3 with a thickness of $4.7 \mathrm{~mm}$. To accelerate saturation in the adhesive layer a specimen width of only $5 \mathrm{~mm}$ was used. Details of the specimen are shown in Fig. 1a. Prior to bonding, the surface of the aluminium substrate was treated using chromic acid etching (CAE) followed by the phosphoric acid anodising (PAA) and then by applying the primer BR127. This treatment process was undertaken at Airbus, Bristol, UK. The film adhesive FM 73M OST was used to bond these substrates. 
Two layers of the adhesive, with dimension approximately (30 x 5) mm were cut and then laid up on both aluminium surfaces. A light pressure was applied to remove air bubbles and to ensure the adhesive made contact with the aluminium surface. The two aluminium substrates were then bonded together in the fixture at a pressure of $0.3 \mathrm{MPa}$ and this pressure was maintained during curing of the adhesive. Steel spacers of thickness of 4.9 $\mathrm{mm}$ were used to maintain the adhesive thickness at $0.2 \mathrm{~mm}$. The specimens were cured in the oven with curing temperature of $120^{\circ} \mathrm{C}$ for 1 hour as recommended by the manufacture [23].

\subsection{Laminated metal doubler}

The test specimens, Fig 1b, were cut from a large curved laminated panel with bonded " $T$ " stiffeners. The laminate was made of aluminium 2024-T3 bonded using the same adhesive as the MSLJ. The laminate consisted of 6 layers of aluminium and 5 layers of adhesive (FM 73 OST), with thicknesses of approximately $1.6 \mathrm{~mm}$ and $0.15 \mathrm{~mm}$ respectively. The stringer bonded onto the laminate panel was aluminium 7055-T7751. The surface treatment of aluminium surfaces and curing temperature and pressure for the adhesive were the same as in the MSLJ. The length and the thickness of the stringers varied from 85-93 $\mathrm{mm}$ and 9.5-10.5 $\mathrm{mm}$ respectively. The thickness of the stringer adhesive layer was not constant along the length due to the curvature of the laminate. It was thinner at the edge $(0.1 \mathrm{~mm})$ and thicker at the centre $(0.2 \mathrm{~mm})$. The doubler specimens (Fig. 1b) contained discontinuities in the form of butts between adjacent co-planar aluminium sheets. The butt region was filled with adhesive. 


\subsection{Specimen ageing}

The ageing of MSLJ and LDB were carried out by immersing the specimens in deionised water at a temperature of $50 \pm 1^{\circ} \mathrm{C}$. The specimens were laid up on the perforated corrugated stainless steel to ensure that all sides of adhesive layer were in complete contact with the water. The specimens were kept in the deionised water for 1 year (wet-1y) and 2 years (wet-2y). FE based diffusion modelling discussed in the partner paper [22] indicated that for the MSLJ (width = $5 \mathrm{~mm}$ ) the adhesive layer had reached saturation within a year and immersion up to 2 years provided prolonged exposure after saturation. The LDB (width $=15 \mathrm{~mm}$ ) was not fully saturated even after 2 years exposure.

\subsection{Mechanical Testing}

For both joint types, after exposure but before fatigue testing, strain gauges (SGs) were attached to the aluminium substrate to monitor the damage in adhesive layer during testing. The centre of the strain gauges was located on the substrate inside the overlap end (e.g see Fig. 1). It is recommended that the centres of gauges are located $1-2 \mathrm{~mm}$ inside the edge of lap [20]. Additional strain gauges were used to get more information on the damage propagation. The position of these extra strain gauges varied. In the labelling of strain gauges, those that were closer to the end of the overlap had odd number as seen in Fig. 1. For LDB testing, the distance from the support roller to the edge of stringer was kept constant at $15 \mathrm{~mm}$, regardless of the stringer length (Fig. 1b). This was sufficient distance to provide access for the in-situ video microscope and ensured that at the overlap ends the relation between the force and the moment was the same in all specimens.

For both MSLJ and LDB, the fatigue testing was performed in load control with a sinusoidal wave form using Instron 1341 servo-hydraulic machine. The stress ratio (R) and 
frequency was 0.1 and $5 \mathrm{~Hz}$ respectively. Based on temperature measurements taken in previous fatigue test programmes specimen heating was not expected to be a problem at this frequency. Two maximum load levels were applied, $60 \%$ and $50 \%$ of the static strength of each condition (unaged and aged) for the MSLJ and $50 \%$ and $40 \%$ of the static strength of each condition (unaged and aged) for LDB. Video microscopy was utilised to visually monitor the damage propagation. Later, it should be noted that the load-life curves for those joints were normalised using the static strength of the unaged condition.

\section{Experimental results}

This paper investigates the fatigue response of monolithic single lap joint and laminated doubler in bending in aged condition. It follows from work reported elsewhere $[24,25]$ that was undertaken investigating the quasi-static response of the same joints in both unaged and aged conditions. The moisture dependent mechanical properties of the adhesive and cohesive zone properties (later used in the FEM) that were developed in this earlier quasistatic work are summarised in Table 1 . The properties were taken to degrade linearly between the limiting values given. The experimental and predicted static response of these joints has been presented in $[24,25]$ and a summary of the experimental and predicted static strengths are shown in Table 2.

\subsection{Monolithic single lap joints}

Fig. 2 shows the load-life response of unaged and aged joints at various load levels. The fatigue life for the aged joints decreased considerably (approximately by factor of 10 at the same load level) compared with the unaged joints. Further aging for a longer time at saturation (wet-2y) only decreased the fatigue life marginally. This is similar to the static response (Table 2) although the damage mechanism will not be the same. In general, the 
degradation of the joints due to combined environmental and fatigue loading is considerably greater than under static loading. Although the degradation is considerable, the failure surfaces of the joints were still cohesive in the adhesive layer for all conditions and all load levels considered. Clearly, the adhesive layer still remained the "weak link", even in the presence of water for sustained periods. This is due to the superior surface preparation used on the substrates.

The failure process of the joints under fatigue loading was monitored using the backface strain technique and in-situ video microscopy. Fig. 3 shows the variation of backface strain with cycles for an un-aged joint fatigued at $60 \%$ of the static strength. The strain gauges for this joint were mounted $1 \mathrm{~mm}$ from the edge of the overlap. Images of the damage in the adhesive layer are also shown at selected cycles at both ends of the overlap. The measured damage zone length at both ends has also been indicated (Fig. 3a). Based on the backface strain evolution, the damage in the adhesive is not symmetric in this specimen. The in-situ video microscopy supported this asymmetric damage as shown in Fig. 3(b-c).

The damage started early at the SG3 side, indicated by the earlier peak in the backface strain curve and the visible damage observed at 1000 cycles (which was approximately 3.5 $\mathrm{mm}$ ) as shown in damage zone length (Fig. 3a). At this number of cycles, the strain has decreased as the visible damage length has passed under the point where the strain gauge was attached ( $1 \mathrm{~mm}$ from the overlap end). As the damage grew further, the strain continued to decrease until failure occurred. On the other hand, at the SG1 side the damage did not grow as fast as the damage at SG3. The strain continued to increase with cycles. Although visible damage has been observed at 1000 cycles, and the length was approximately $2 \mathrm{~mm}$ at 2000 cycles (beyond the SG1 position), the strain still continued to 
increase. This was not similar to the strain evolution at SG3, due to asymmetric damage growth. The degree of asymmetric damage growth (and so backface strain) will be different from joint to joint.

Fig. 4 shows the backface strain response at a fatigue load level of 50\% in a wet condition (wet-1y). The strain gauges were attached $2 \mathrm{~mm}$ inside the overlap end. The asymmetry in the damage growth was not as extreme as that shown in Fig. 3. In fact, both strains reach a peak at a similar stage. The corresponding observed damage zone length is also shown providing further evidence of symmetric damage. Damage growth in the wet condition is faster than in the dry condition at the same load level. In the wet condition, it is difficult to determine the damage initiation phase as the backface strain increased from the beginning of test. In general, it can be seen that the backface strain peaked when the damage reached the SG and then decreased when it passed beyond the SG.

\subsection{Laminated doubler in bending (LDB)}

Fig. 5 shows the fatigue life of LDB. The load level of all specimens has been normalised by the unaged static strength (Table 2). It seems that the reduction of fatigue life for wet-1y and wet-2y is not very different. Further, it can be said that the reduction factor in fatigue life for wet-1y and wet-2y is in the range 2.5-3 of the dry fatigue life at a specified load level. It can be seen that at lower loads the fatigue life of wet-2y was higher than of wet$1 \mathrm{y}$. This is possibly due to the different rate of failure of fillet between wet-1y and wet-2y at this load level. This will be explained when considering the fatigue failure process of LDB below.

Fig. 6 shows the backface strain evolution of LDB due to fatigue loading for dry and wet conditions at one side of the bonded stringer. The positions of the strain gauges are shown 
in Fig. 1b. The ratio between transition point of the damage initiation (the point at which the strain gradient begins to increase significantly) and total life for dry, wet-1y and wet-2y at the load levels considered are approximately $0.21,0.12$ and 0.06 respectively, indicating that the damage propagated later for dry and earlier for wet-1y and wet-2y specimens. Further, it is seen in the dry condition that the strain jump is more rapid than in the wet condition. For dry-1, wet-1y and wet-2y, the fillet size is approximately the same, while in dry-2 the fillet size is much larger at both ends (Fig. 7). It can be seen that a very rapid and high strain jump occurred in the dry-2 specimen (Fig. 6b) and it occurred almost at the end of its life. This could be due to the different fillet failure rate (compare Fig. 6a and b) and this will be discussed further in the finite element modelling section later.

The longer fatigue life of the wet-2y than wet-1y at low load levels is likely caused by the different rate of fillet failure. It can be seen in Fig. 7(e-f) that in wet-1y the failure of fillet is interfacial. This is a result of corrosion in the stringer. However, in wet-2y the failure of the fillet is cohesive in the adhesive. It can also be seen in Fig.7(c-d) that at higher load levels the failure of fillet is the same for wet-1y and wet-2y, (cohesive in the fillet) and the fatigue life of wet-2y is slightly lower than that of wet-1y, as expected.

Fig. 8 shows the failure process of LDB in fatigue in a dry specimen at a load level of 0.38 . For clarity, only the backface strain SG3 and SG4 are shown (Fig. 8a), adjacent to where the damage was observed (Fig. 8b). It can be seen that at point 1, around 52,000 cycles, the damage started at the corner at the end of the overlap (indicated by black arrow in image 1). Soon after this, the strain at SG4 exceeded the strain at SG3. This indicates that the damage in the bondline has probably gone beyond $2 \mathrm{~mm}$ from the overlap end (i.e beyond SG3). With increasing cycles to point 2 (67,500 cycles) the damage propagated into both 
the adhesive layer and the fillet (image 2). Starting from 72,000 cycles the strain increased rapidly as the damage in the fillet propagated rapidly. When the fillet was fully damaged, the strain reached a maximum value (point 3 ) at 74,500 cycles. The damage in the adhesive layer at this point has propagated to approximately $5.5 \mathrm{~mm}$ from the edge (image 3). This corresponds with the damage passing SG4. This failure process indicates the importance of the fillet in the damage evolution and the fatigue life of this joint. The failure surfaces of the main bondline in the joints in all conditions at all load levels were cohesive in the adhesive. As stated above this was not always the case for the fillet bond.

There will be some inevitable desorption of moisture from the specimens whilst being fatigued. Simple diffusion calculations indicate that, even for the longest fatigue tests, this will only effect a very small region at the overlap end. This may have the effect of slightly enhancing the fatigue lives, which will be more noticeable at lower loads where the fatigue test duration is longer.

\section{Finite element modelling}

\subsection{Modelling approach}

The empirical strain-based fatigue model of Coffin-Manson has been widely used to predict the fatigue life of material where there is localised plastic deformation such as in a notch, or similar stress raiser [26]. In adhesively bonded joints, at the end of the overlap, there is stress concentration which can be a site of localised strain. Thus, a strain-based fatigue model may be applicable to predict the fatigue life of an adhesively bonded joint and such use has been reported in the literature [13-15]. 
The fatigue damage was simulated by applying the maximum fatigue load statically in an incremental manner, each increment representing a block of cycles (Fig. 9). The material properties were degraded as the damage evolved during fatigue loading until the joint could no longer sustain the maximum fatigue load. Damage evolution during fatigue loading was modelled according to the strain-based fatigue damage algorithm shown in Eq. (1a).

$$
\begin{aligned}
& \frac{\Delta D_{F}}{\Delta N}= \begin{cases}\alpha\left(\varepsilon_{\text {max }}-\varepsilon_{\text {th }}\right)^{\beta}, & \varepsilon_{\text {max }}>\varepsilon_{\text {th }} \\
0, & \varepsilon_{\text {max }} \leq \varepsilon_{\text {th }}\end{cases} \\
& \varepsilon_{\text {max }}=\frac{\varepsilon_{n}}{2}+\sqrt{\left(\frac{\varepsilon_{n}}{2}\right)^{2}+\left(\frac{\varepsilon_{s}}{2}\right)^{2}}
\end{aligned}
$$

$\Delta D_{F}$ is the increment of fatigue damage, $\Delta N$ is the cyclic increment, $\varepsilon_{\max }$ is the maximum principal strain as expressed in Eq. (1b), $\varepsilon_{t h}$ is the threshold strain, $\varepsilon_{n}$ and $\varepsilon_{s}$ are the normal strain and shear strain respectively, and $\alpha$ and $\beta$ are material parameters. The threshold strain is related to the endurance limit, below which no fatigue damage can occur. Parameters $\alpha, \beta$ and $\varepsilon_{t h}$ require calibration using experimental fatigue life data. The approach adopted here has been to determine (calibrate) the fatigue parameters using the dry MSLJ fatigue response and use these calibrated parameters to predict the response of the other configurations. It will be seen that this has been possible for all but the dry LDB configuration and discussion of this has been given in the relevant sections below.

\subsection{Modelling the fatigue response of monolithic single lap joints}

The FE modelling of both unaged and aged MSLJ (1 year and 2 years) was performed in a 2D model since the associated diffusion analysis had indicated that the adhesive was 
completely saturated with the water after 1 year. The FE modelling was performed using ABAQUS standard FE code [25]. Both thermal and swelling strains were included in the model. The bilinear traction-separation law of the cohesive zone model (CZM) (see Fig. 10a) has been successfully used to predict progressive damage and residual strength in the unaged and aged MSLJ and LDB [24, 25]. This approach has been further extended in this fatigue modelling. A detailed study of the effect of the CZM parameters and associated mesh convergence on the response of the MSLJ has been reported elsewhere [25] for the dry joint. For the aged joints, the adhesive and the cohesive zone properties (i.e the normal and shear of traction, stiffness and fracture energy) were reduced due to moisture uptake [26 and Fig $10 \mathrm{~b}$ ]. The moisture degraded parameters were then degraded further to accommodate the fatigue damage, as schematically shown in Fig. 10 c. The values of the degraded adhesive and cohesive zone properties used in the modelling of the static failure of the aged joints [25] can be seen in Table 1 for 1 year and 2 years aging. The CZM was located at the middle of the adhesive layer. The boundary conditions and meshing of the MSLJ FE model is shown in Fig. 11. The substrate and the adhesive layer were modelled using plane stress (CPS4) and plane strain (CPE4) elements respectively. The mesh size of the cohesive element was $0.02 \mathrm{~mm}$ x $0.1 \mathrm{~mm}$. The maximum load applied was applied sequentially, following thermal analysis (for unaged joint) and thermal and swelling analyses (for aged joints). As in the modelling of the statically loaded aged joints in the partner paper [24], the fillet was not included in the MSLJ but was in the LDB models. The basis for this was that in the former joints the fillets were small and were not well bonded to the substrate and thus did not provide significant load transfer. This was not the case with the LDB joints. 
To implement the fatigue model, there are two load steps (Fig. 9). The first step is a ramped loading to the maximum fatigue load $\left(P_{\max }\right)$. In the second step, the applied load is maintained constant at $P_{\max }$. In the first step, some static damage in the cohesive element might occur depending on the applied $P_{\max }$. The cohesive zone law parameters (elastic modulus, traction, and fracture energy) were then degraded following the strain-based cyclic damage law (see Eq. 1). The fatigue damage parameter $\left(D_{F}\right)$ was updated with each increment of cycles $(\Delta N)$. The degraded material properties produced new maximum principal strains, which were also updated. This process continued until the material was no longer able to sustain the maximum fatigue load, at which point the joint failed. The fatigue life was calculated from the accumulated time (cycles) in the $2^{\text {nd }}$ step.

The fatigue parameters $\left(\alpha, \beta\right.$, and $\left.\varepsilon_{t h}\right)$ in strain-based fatigue model have to be calibrated against the experimental data to obtain appropriate values. Khoramishad [28] conducted a parametric study on the effect of these parameters on the fatigue life. Increasing $\alpha$ accelerated the fatigue damage evolution and led to decreasing fatigue life with no dependency on the load level applied. On the other hand, increasing $\beta$ and $\varepsilon_{t h}$ decelerated fatigue damage evolution and therefore increased the fatigue life. The effect of both $(\beta$ and $\left.\varepsilon_{t h}\right)$ was more pronounced at lower load levels when the strain is lower. Knowing the effect of the fatigue parameters on the fatigue life, an iterative method was used in conjunction with the unaged fatigue joint responses (load-life and load-backface strain) to obtain appropriate values so that the predicted fatigue life was in good agreement with the experimental data. These data were then used to predict the fatigue responses of the aged joints. The effect of cyclic increment size was considered in the calibration. The convergence was obtained at increment sizes $\leq 1 \%$ of experimental fatigue life $\left(N_{f} / 100\right)$. 
Thus, the maximum increment size equal to $N_{f} / 100$ was considered reasonable and was used in this fatigue modelling. The fatigue parameters for MSLJ are seen in Table 3.

The backface strain has been shown to be a useful means of calibrating the cohesive zone properties and of characterising the damage process in static loading [24,25]. In fatigue, it is also very useful for monitoring the damage evolution in the adhesive layer and thus was used here to calibrate the fatigue damage model parameters. Different material degradation (damage evolution) models was assessed during fatigue loading and shown in Fig. 12. Essentially, two modes of degradation were considered: i) linear degradation, ii) nonlinear degradation. In the former the cohesive properties degrade linearly from the undamaged $\left(D_{F}=0\right)$ to the fully damaged $\left(D_{F}=1\right)$ state. In nonlinear degradation, the material properties degrade rapidly at low fatigue damage and then more slowly at high fatigue damage. At the maximum fatigue degradation $\left(D_{F}=1\right)$, the cohesive properties do not degrade to zero. This corresponds with the threshold properties in which the fatigue failure occurs only if the maximum fatigue load is greater than a threshold value. The calibration of this model was characterised using backface strain technique during the fatigue loading. For the dry MSLJ, as seen in Fig. 13a, the non-linear degradation seems to show better agreement with the experimental backface strain than the linear degradation model. Further, the nonlinear fatigue degradation for MSLJ was used in wet conditions; however when wet it degraded more than in a dry condition (see Fig. 12). This is consistent with the experimental backface strain result. Higher degradation in the early cycles was observed in dry and wet condition at both $60 \%$ and $50 \%$ load levels, however the degradation was more pronounced in the wet condition than that in the dry condition. 
The predicted fatigue life for MSLJ, as seen in Fig. 2, shows good agreement with the experimental data. The residual stresses due to thermal and swelling strain were assessed in the modelling. When included they decreased the fatigue life by approximately $8 \%$.

Further, the agreement between the predicted and experimental backface strain and damage zone length was found, for example, in aged (wet-1y) MSLJ at load level of $50 \%$ as shown in Fig. 14. The strain gauge was attached $2 \mathrm{~mm}$ inside the end of overlap and the FE predictions were obtained assuming symmetric damage. It seems that at cycles up to $N / N_{f}=$ 0.5 , the predicted backface strain is lower than the experimental data and at higher cycles the backface strain is in good agreement with the experiment data. In the same way, the predicted damage zone length is also under predicted in the early cycles (up to $N / N_{f}=0.5$ ) and beyond this good agreement is obtained. This disagreement at the early cycles is possibly due to the failure of the fillet, which experimentally occurs at the adherend-fillet interface, and was not included in the FE modelling.

\subsection{Modelling fatigue response of laminated doubler in bending}

The FE model of the LDB was modelled in 3D, because the joint had not reached the saturation level and it was necessary to determine the spatial distribution at $1 \mathrm{yr}$ and $2 \mathrm{yr}$. This has been discussed in a little more detail in the partner paper [22]. The properties used in the FE of the aged joint (adhesive in the bonded stringer and laminate and cohesive zone model) were the same as the MSLJ (see Table 1). Fig. 16 shows the meshing and boundary conditions applied to the LDB. As the failure in LDB was in the bondline between laminate and stringer, the cohesive element (COH3D) was used only in this bondline. The thickness of the adhesive in the bondline varied linearly, from $0.1 \mathrm{~mm}$ at the end of the overlap to $0.2 \mathrm{~mm}$ at the middle, however the thickness of cohesive element was uniform, $0.02 \mathrm{~mm}$, located in the middle of the adhesive layer and through the fillet, matching the observed path of failure. The mesh size of the CZM in the bondline and in the fillet was 
$0.25 \times 0.25 \mathrm{~mm}$ and $0.098 \times 0.25 \mathrm{~mm}$ respectively. The aluminium layers, stringer, and adhesive were modelled as 8-node linear bricks (C3D8). Tie constraints were applied between the aluminium and main bondline surfaces.

The thermal and swelling strains were included in the FE model following the same procedure as the MSLJ. As the LDB was not saturated, the properties of adhesive vary according to the moisture content. This is achieved in ABAQUS by defining field variable dependent material properties. As with the MSLJs, the effect of time of exposure (1 year or 2 years) on properties was accommodated by having separate degradation curves for 1 year and 2 years exposure.

A summary of predicted static strength is seen in Table 1, while Fig. 5 shows the predicted fatigue life of the LDB in unaged and aged conditions using fatigue parameters shown in Table 3. In general, good agreement was seen between the predicted and experiment data in all conditions. However, the wet-2y predicted result was slightly under predicted at load level $\left(\mathrm{P}_{\max } / \mathrm{P}_{\mathrm{s}(\mathrm{dry})}\right)=0.4$ and over predicted at a lower load level (i.e $\mathrm{P}_{\mathrm{max}} / \mathrm{P}_{\mathrm{s}(\mathrm{dry})}=0.33$ ). As discussed earlier (see section 3.2), this is due to the different rates of failure of the fillets. The fillet size in this modelling is the average size and there is considerable variation of the fillet size in practice. The swelling and thermal residual strains were included in the model. The residual stresses these induced did not affect the predicted static strength of LDB. However, they did affect the fatigue life of the joints. A $30 \%$ reduction of fatigue life has been found by including those residual stresses.

The different value of $\alpha$ between the calibrated MSLJ and the unaged (dry) LDB (see Table 3) is possibly due to differences in manufacturing of the joints and the age of the 
adhesive. However, in aged conditions the fatigue parameters of MSLJ and LDB are the same. This perhaps indicates that the effect of manufacturing and age of an adhesive is not as significant when considering moisture degraded joints. A further difference in fatigue degradation between MSLJ and LDB may be due to mode mixity. Currently both mode I and mode II parameters experience the same degree of cyclic degradation as this is the simplest and as data is only available from two different configurations. It may be that the mode I and mode II parameters degrade at different rates. To investigate this would require additional joint configurations having other mode mixities and this needs to be studied further in the future. In LDB (see Fig. 13b), a linear fatigue degradation model shows better agreement with the experimental backface strain. Another difference between predicted (using a linear fatigue degradation) and experimental backface strains is the adhesive fillet, which was not included in this calibration. The effect of fillet is discussed below.

Fig.16 shows the predicted backface strain of an unaged LDB, located $4 \mathrm{~mm}$ inside the overlap end at load level $\left(\mathrm{P}_{\max } / \mathrm{P}_{\mathrm{s}(\mathrm{dry})}\right)$ of 0.53 . Using a 3D model, compared with experimental data, the predicted backface strain increase (or jump) occurred earlier, however the value of maximum strain from the 3D model was in good agreement with the experimental data. It is possible that the predicted failure at the end of the overlap region, which included the fillet, was in error. To consider the different failure paths in this region, a 2D FEM model was created with the different sizes of fillet; without fillet (F0), small fillet (F1) and big fillet (F2). The FE boundary condition, mesh and fillet size are as seen in Fig. 17. The failure of the fillet was modelled by putting the cohesive element in the fillet, with the cohesive element thickness approximately $0.02 \mathrm{~mm}$. The mesh size in the cohesive element was $(0.02 \times 0.1) \mathrm{mm}$. As seen in Fig. 16 , for LDB without a fillet (F0) 
the strain jump occurred at $N / N_{f}=0.2$ and the maximum strain is considerably lower than the experimental data. Introducing a small fillet (F1) shifted the strain jump to $N / N_{f}=0.6$ which is close to the experiment data. The maximum strain was also only slightly lower than the experiment data. Increasing again the size of fillet (F2) shifted the strain jump to $N / N_{f}=0.9$, close to the end of fatigue life. Thus, the size of fillet affects the fatigue damage evolution and finally the predicted fatigue life. Using the same fatigue damage model parameters the fatigue life increases with increasing fillet size. To illustrate this, the fatigue life of LDB without a fillet (F0), with a small fillet (F1) and with a big fillet (F2) was 2,000 cycles, 2,857 cycles, and 6,044 cycles respectively at load level of 0.53.

To get a better understanding of the fatigue failure process of LDB, the 2D (F2) model damage evolution at a load level of $40 \%$ in an unaged condition is presented in Fig 18. This can also be compared with the experimental failure process at the same load level. The fillet size in the FE 2D model is shown in Fig. 17c. The fillet in the actual specimen is also big, but it is not a triangle (see Fig. 7b). Nevertheless, the length of the failure path is approximately the same, so the triangular fillet can be considered to be representative. Fig. 18 shows the variation of the backface strain with cycles and contour plots of predicted fatigue damage at selected numbers of cycles. The backface strain gauge was attached on the laminate at $4 \mathrm{~mm}$ inside the end of overlap. For comparison, the experiment backface strain is also shown (Fig. 18a). It seems that the agreement between FEM and experiment backface strain is good. In Fig. 18b, at low cycles (point 1), a little fatigue damage, indicated by the SDV1, is observed, localised in the corner of the end of overlap. The damage then propagates stably with increasing cycles into the centre of the bondline and the fillet of the joints; however, it is faster in the bondline. This stable damage propagation is indicated by a gradually increasing backface strain (point 2-3). Beyond point 3 the 
backface strain starts to rise rapidly (as the damage propagation in the fillet increases) and it reaches a peak point (when the fillet nearly fails, point 4). At this point, the observed damage zone length in the bondline is approximately $5.5 \mathrm{~mm}$ which is very close to that observed in experiment $(\approx 5.5 \mathrm{~mm}$ ) (see Fig. $8 \mathrm{~b}(3)$ and Fig. 18b(4)). After the fillet failed, rapid damage propagation to the centre of the bondline occurred until the joint failed. Thus, based on the backface strain and fatigue damage contour, it appears that in fatigue loading the fillet plays an important role in the damage evolution and also the fatigue life of the LDB.

\section{Conclusions}

Fatigue testing and FE modelling of unaged and aged MSLJ and LDB have been undertaken. Some important findings obtained are outlined below:

a. The moisture degraded the fatigue life of the joints (MSLJ and LDB). The fatigue life decreased with increasing moisture content, levelling off when approaching moisture saturation. The moisture also caused the damage initiation to occur earlier in the aged than in the unaged joints.

b. The backface strain technique has been successfully employed to monitor the fatigue damage evolution in the adhesive layer in both MSLJ and LDB. This technique was also found to be a useful means of calibrating the fatigue parameters in both MSLJ and LDB.

c. The strain-based cyclic damage applied to the cohesive zone model has been successfully utilised to model the fatigue response of the unaged and aged the joints, in terms of the failure load and the failure process. Non-linear fatigue degradation of the cohesive zone model parameters gave better agreement with the MSLJ experiment data, whereas, linear fatigue degradation appeared to be more appropriate for LDB. 
d. The adhesive fillet was found to play an important role in the fatigue damage evolution and predicted fatigue life of the LDB.

\section{Acknowledgement}

The authors would like to thanks to Airbus (Bristol, UK) which has supplied the laminated doubler material and for the surface treatment of aluminium. Also thanks to Directorate General of Higher Education, Ministry of Education, Republic of Indonesia which support funding in this research.

\section{References}

[1] A.J. Kinloch, Adhesion and Adhesives: science and technology, Chapman \& Hall, London, 1987.

[2] M. Fernando, W.W. Harjoprayitno, A.J. Kinloch, A fracture mechanics study of the influence of moisture on the fatigue behaviour of adhesively bonded aluminium-alloy joints, Int. J. Adhesion and Adhesives 16 (1996) 113-119.

[3] A.J. Kinloch, M.S.G. Little, J.F. Watts, The role of the interphase in the environmental failure of adhesive joints, Acta Materialia 48 (2000) 4543-4553.

[4] J.K. Jethwa, and A.J. Kinloch, The fatigue and durability behaviour of automotive adhesives. Part I: Fracture mechanic tests, Journal of Adhesion 61 (1997) 71-95.

[5] M.-L. Abel, A.N.N Adams, A.J. Kinloch, S.J. Shaw, J.F. Watts, The effects of surface pretreatment on the cyclic-fatigue characteristics of bonded aluminium-alloy joints, Int. J. Adhesion and Adhesives 26 (2006) 50-61.

[6] P. Briskham, and G. Smith, Cyclic stress durability testing of lap shear joints exposed to hot-wet conditions, Int. J. Adhesion and Adhesives 20 (2000) 33-38. 
[7] K.M. Liechti, G.A. Arzoumanidis, S.-J. Park, Fatigue fracture of fully saturated bonded joints, The Journal of Adhesion 78 (2002) 383-411.

[8] J.A.M. Ferreira, P.N. Reis, J.D.M. Costa, M.O.W. Richardson, Fatigue behaviour of composite adhesive joints, Composite Science and Technology 62 (2002) 1373-1379.

[9] O. Nguyen, E.A. Repetto, M. Ortiz, and R.A. Radovitzkya, Cohesive model of fatigue crack growth, International Journal of Fracture110 (2001) 351-369.

[10] S. Maiti, and P.H. Geubelle, A cohesive model for fatigue of polymers, Engineering Fracture Mechanics 72 (2005) 691-708.

[11] K.L. Roe, and T. Siegmund, An irreversible cohesive zone model for interface fatigue crack growth simulation, Engineering Fracture Mechanics 70(2) (2003) 209-232.

[12] P. Robinson, U. Galvanetto, D. Tumino, G. Bellucci, and D. Violeau, Numerical simulation of fatigue-driven delamination using interface elements, International Journal for Numerical Methods in Engineering 632(2005) 1824-1848.

[13] A.G. Solana, A.D. Crocombe, and I.A. Ashcroft, Fatigue life and backface strain predictions in adhesively bonded joints, Int. J. Adhesion and Adhesives 30 (2010) $36-42$.

[14] H. Khoramishad, A.D. Crocombe, K.B. Katnam, I.A. Aschroft, Predicting fatigue damage in adhesively bonded joints using a cohesive zone model, International Journal of Fatigue 32(7) (2010) 1146-1158.

[15] H. Khoramishad, A.D. Crocombe, K.B. Katnam, I.A. Aschroft, A generalised damage model for constant amplitude fatigue loading of adhesively bonded joints, Int. J. Adhesion and Adhesives 30 (2010) 513-521.

[16] T. Diehl, On using a penalty-based cohesive-zone finite element approach, Part I: Elastic solution benchmarks, International Journal of Adhesion and Adhesives 28 (2008) 237-255. 
[17] T. Diehl, On using a penalty-based cohesive-zone finite element approach: Part II Inelastic peeling of an epoxy-bonded aluminium strip, International Journal of Adhesion and Adhesives 28 (2008) 256-265.

[18] H. Abe, and T. Satoh, Non-destructive detection method of fatigue crack in spotwelded joints, YosetsuGakkaiRonbunshu/Quarterly Journal of Japan Welding Society 4(4) (1986) 666-673.

[19] Z.H. Zhang, J.K. Shang, F.V. Lawrence, A backface strain technique for detecting fatigue-crack initiation in adhesive joints, Journal of Adhesion 49(1-2) (1995) 23-36.

[20] A.D. Crocombe, C.Y. Ong, C.M. Chan, M.M.A. Wahab, Investigating fatigue damage evolution in adhesively bonded structures using backface strain measurement, Journal of Adhesion 78(9) (2002) 745-776.

[21] A.G. Solana, A.D. Crocombe, M.M. Abdel Wahab, and I.A. Ashcroft, Fatigue initiation in adhesively-bonded single-lap joints, Journal of Adhesion Science and Technology 21(14) (2007) 1343-1357.

[22] M. Quaresimin, and M. Ricotta, Life prediction of bonded joints in composite materials, International Journal of Fatigue 28 (10) (2006) 1166-1176.

[23] Cytec Engineered Materials, FM ${ }^{\circledR} 73$ toughened epoxy film, Technical Service, 1300 Revolution Street, Havre de Grace, Maryland, 1998.

[24] S. Sugiman, A.D. Crocombe, Experimental and numerical studies on the static response of aged adhesively joints, Int. J. Adhesion and Adhesives (2012) Submitted.

[25] S. Sugiman, A.D. Crocombe, Modelling the static response of unaged adhesively bonded structures, Engineering Fracture Mechanic (2012) Submitted.

[26] X. Zheng, On some basis problems of fatigue research in engineering, International Journal of Fatigue 23 (2001) 751-766.

[27] ABAQUS, User manual, version 6.9.1, Habbit, Karlsson\& Sorensen, Inc., USA, 2009. 
[28] H. Khoramishad, Modelling fatigue damage in adhesively bonded joints, PhD Thesis, University of Surrey, Guildford, UK, 2010.

\section{List of Tables}

Table 1. The properties of aged adhesive and cohesive used in the FEM of MSLJ [22, 23].

Table 2. Static strength of MSLJ and LDB in dry and wet condition [22, 23]

Table 3. The fatigue parameters for MSLJ and LDB.

Table 1. The properties of aged adhesive and cohesive used in the FEM of MSLJ [22, 23].

\begin{tabular}{lc|cccccc}
\hline Adhesive & \multicolumn{7}{|c}{ Cohesive } \\
\hline Condition & $\begin{array}{c}E \\
(\mathrm{MPa})\end{array}$ & $\begin{array}{c}K_{n} \\
\left(\mathrm{~N} / \mathrm{mm}^{3}\right)\end{array}$ & $\begin{array}{c}K_{s}=K_{t} \\
\left(\mathrm{~N} / \mathrm{mm}^{3}\right)\end{array}$ & $\begin{array}{c}T_{n} \\
(\mathrm{MPa})\end{array}$ & $\begin{array}{c}T_{s}=T_{t} \\
(\mathrm{MPa})\end{array}$ & $G_{I C}\left(\mathrm{~kJ} / \mathrm{m}^{2}\right)$ & $\begin{array}{c}G_{\text {IIC }}=G_{\text {IIIC }} \\
\left(\mathrm{kJ} / \mathrm{m}^{2}\right)\end{array}$ \\
\hline Dry & 2300 & 100,000 & 35,750 & 53 & 30.5 & 2.5 & 5 \\
1 year & 1960 & 80,000 & 28,550 & 39.1 & 23 & 2.1 & 4.2 \\
2 year & 1862 & 79,250 & 28,350 & 35.8 & 21 & 1.98 & 3.96
\end{tabular}

Table 2. Static strength of MSLJ and LDB in dry and wet condition [22, 23]

\begin{tabular}{lcccc}
\hline \multirow{2}{*}{ Condition } & \multicolumn{2}{c}{ Exp. failure load } & \multicolumn{2}{c}{ Predicted failure load } \\
\cline { 2 - 5 } & MSLJ $(\mathrm{kN})$ & LDB $(\mathrm{kN})$ & MSLJ $(\mathrm{kN})$ & LDB $(\mathrm{kN})$ \\
\hline Dry & $3.93 \pm 0.08$ & $5.05 \pm 0.09$ & 3.95 & 4.81 \\
Wet-1y & $3.06 \pm 0.14$ & $4.34 \pm 0.10$ & 3.10 & 4.30 \\
Wet-2y & $2.97 \pm 0.11$ & $4.02 \pm 0.05$ & 2.87 & 4.08 \\
\hline
\end{tabular}

Table 3. The fatigue parameters for MSLJ and LDB.

\begin{tabular}{lccc}
\hline \multicolumn{1}{c}{ Type of joint } & $\alpha$ & $\beta$ & $\varepsilon_{\text {th }}$ \\
\hline MSLJ (dry and wet) & 0.0015 & 2.5 & 0.01 \\
\hline LDB & & & \\
- Unaged (dry) & 0.003 & 2.5 & 0.01 \\
- Aged (wet-1y and wet-2y) & 0.0015 & 2.5 & 0.01 \\
\hline
\end{tabular}




\section{List of Figures}

Fig. 1 The specimen and dimensions of (a) monolithic single lap joint, (b) laminated doublers loaded in bending. The stringer web is removed in the figure (b).

Fig. 2. The fatigue life of MSLJ in unaged and aged condition. The load level is normalised by the unaged static strength.

Fig. 3 The unaged MSLJ failure process with fatigue loading at a load level of $60 \%$. (a) Showing the variation of backface strain (BFS) and damage zone (DZ) size with cycles, (b,c) Showing the images of the damage in the adhesive layer at a selected number of cycles at both ends. Black arrows show approximately the tip of the damage.

Fig. 4 The variation of backface strain with number of cycles for an aged MSLJ (wet-1y) due to fatigue loading at a load level of $50 \%$.

Fig. 5 Fatigue life of doublers loaded in bending in dry and wet conditions. The load level is normalised by the unaged static strength.

Fig. 6 Backface strain versus number of cycles of doublers in bending in (a) dry-1 (load level of 0.53), (b) dry-2 (load level of 0.38), (c) wet-1y (load level of 0.4), (d) wet$2 \mathrm{y}$ (load level of 0.4 ).

Fig.7 The fatigue failure in the fillet in LDB, (a) dry-1 (load level of 0.53), (b) dry-2 (load level of 0.38), (c) wet-1y (load level of 0.5), (d) wet-2y (load level of 0.5 ) (e) wet$1 \mathrm{y}$ (load level of 0.4 ), (f) wet-2y (load level of 0.4 ).

Fig. 8 The fatigue failure process of LDB (dry at load level of 0.38). (a) Backface strain history (b) Images of failure.

Fig. 9 Modelling approach of fatigue loading.

Fig. 10 The schematic of moisture and fatigue degradation of cohesive zone.

Fig. 11 The boundary condition and mesh of MSLJ.

Fig.12 Fatigue degradation of the cohesive zone parameters.

Fig.13 Predicted and experimental backface strains in unaged (a) MSLJ, (b) LDB.

Fig. 14 The predicted backface strain (BFS) and damage zone (DZ) length of aged (wet-

$1 \mathrm{y})$ MSLJ at load level ( $\left.\mathrm{P}_{\max } / \mathrm{P}_{\mathrm{s} \text { (wet-1y) }}\right)$ of $50 \%$.

Fig. 15 FE boundary condition and meshing of LDB

Fig. 16 The predicted backface strain of LDB in dry condition 
Fig.17 The fillet in FE 2D model (a) without fillet (F0), (b) small fillet (F1), (c) big fillet (F2).

Fig. 18 (a) Backface strain vs. with the normalised number of cycles of LDB at load level $40 \%$ in dry condition, (b) The contour plot of fatigue damage.

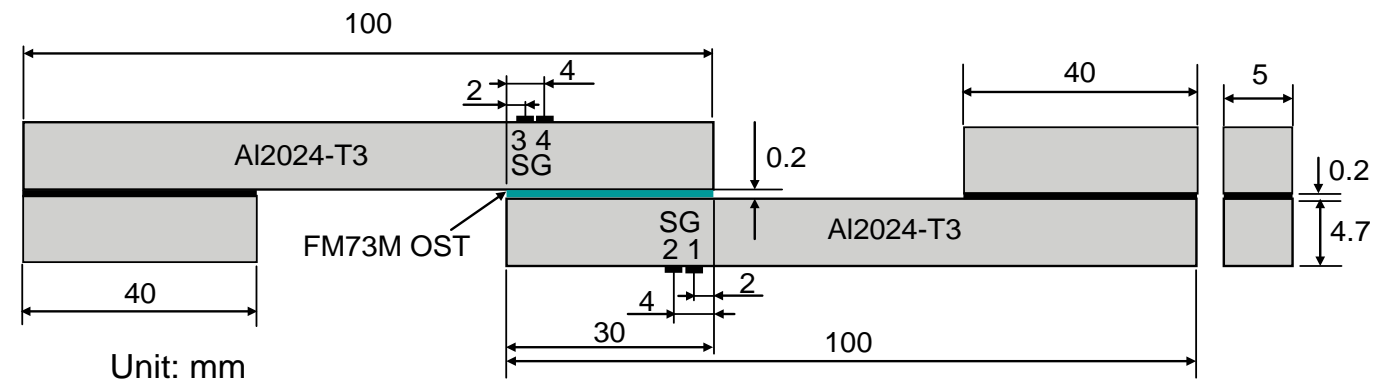

(a)

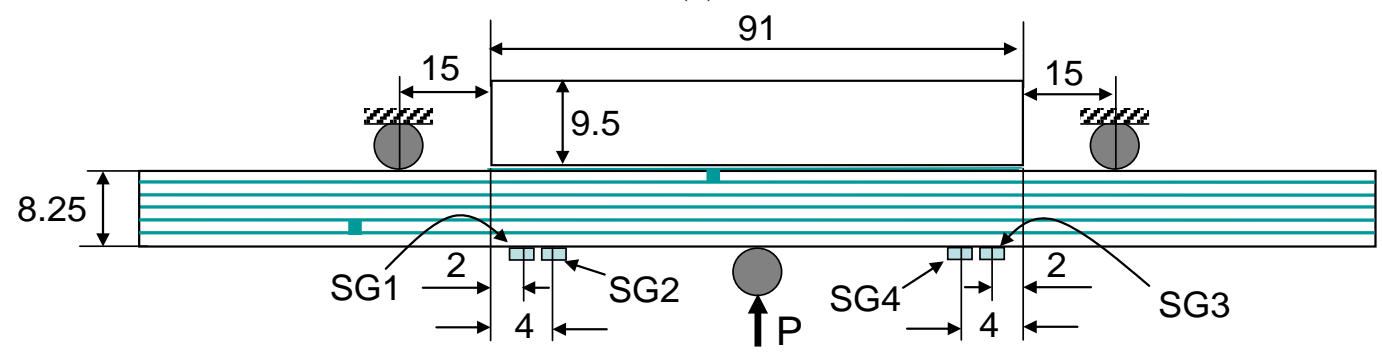

Specimen width: $15 \mathrm{~mm}$

Unit: $\mathrm{mm}$

(b)

Fig. 1 The specimen and dimensions of (a) monolithic single lap joint, (b) laminated doublers loaded in bending. The stringer web is removed in the figure (b). 


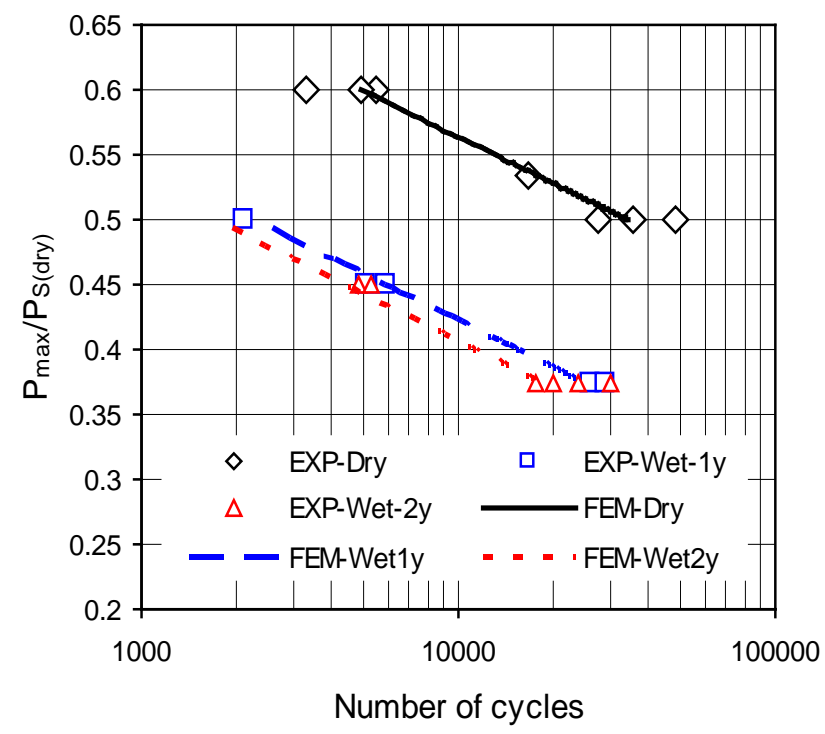

Fig. 2. The fatigue life of MSLJ in unaged and aged condition. The load level is normalised by the unaged static strength.

(a)

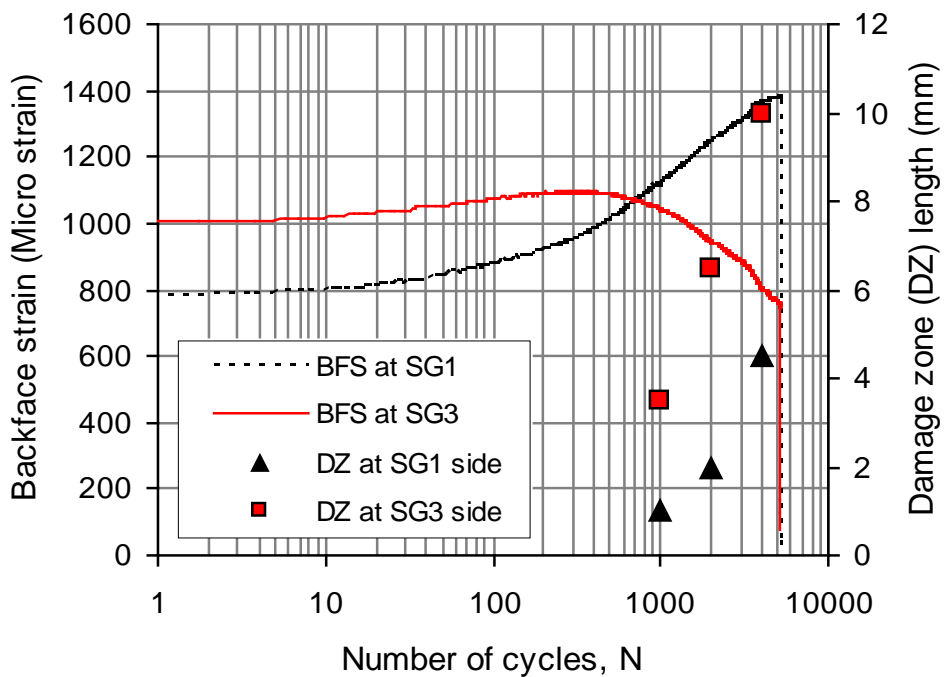

(b)
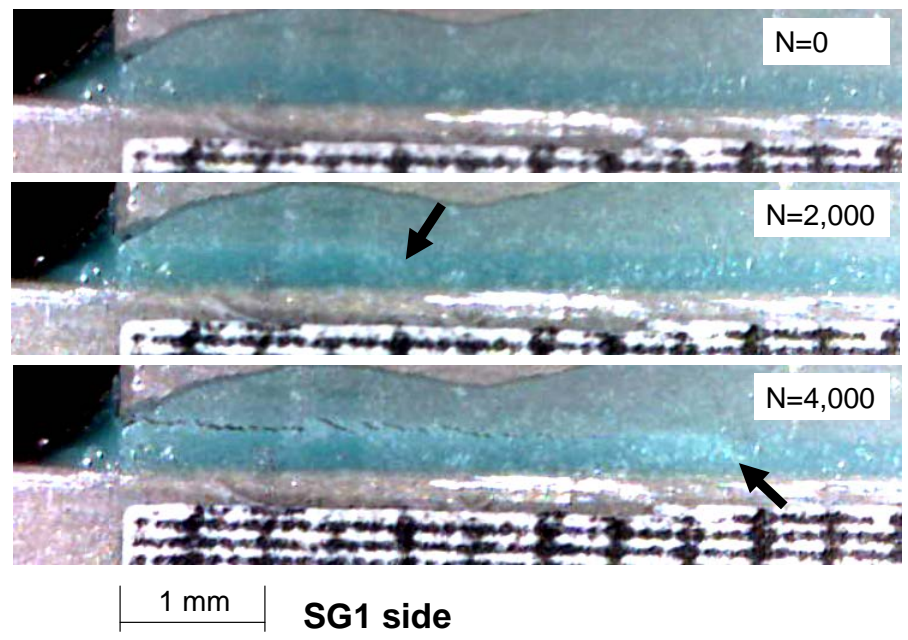

(c) 


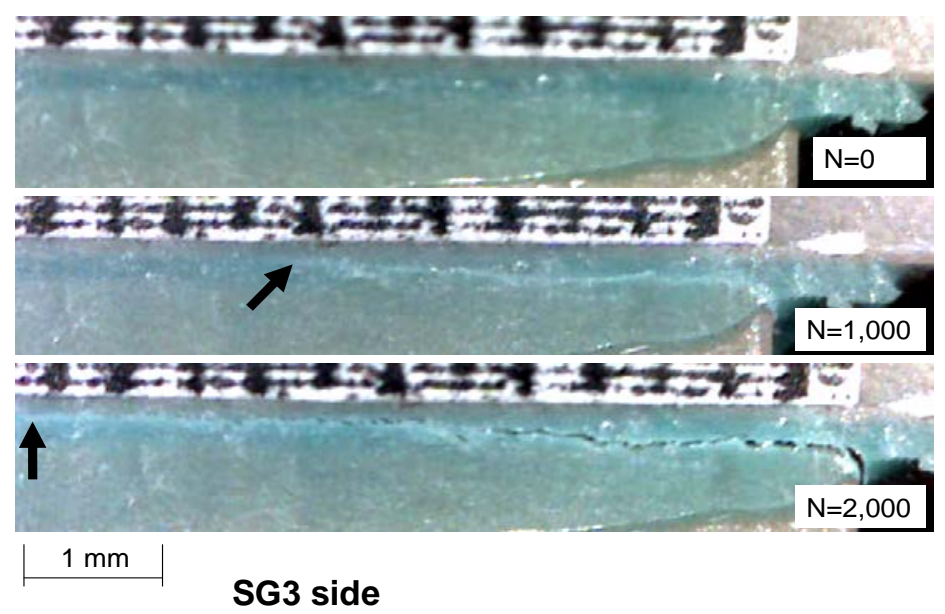

Fig. 3 The unaged MSLJ failure process with fatigue loading at a load level of $60 \%$. (a) Showing the variation of backface strain (BFS) and damage zone (DZ) size with cycles, $(b, c)$ Showing the images of the damage in the adhesive layer at a selected number of cycles at both ends. Black arrows show approximately the tip of the damage.

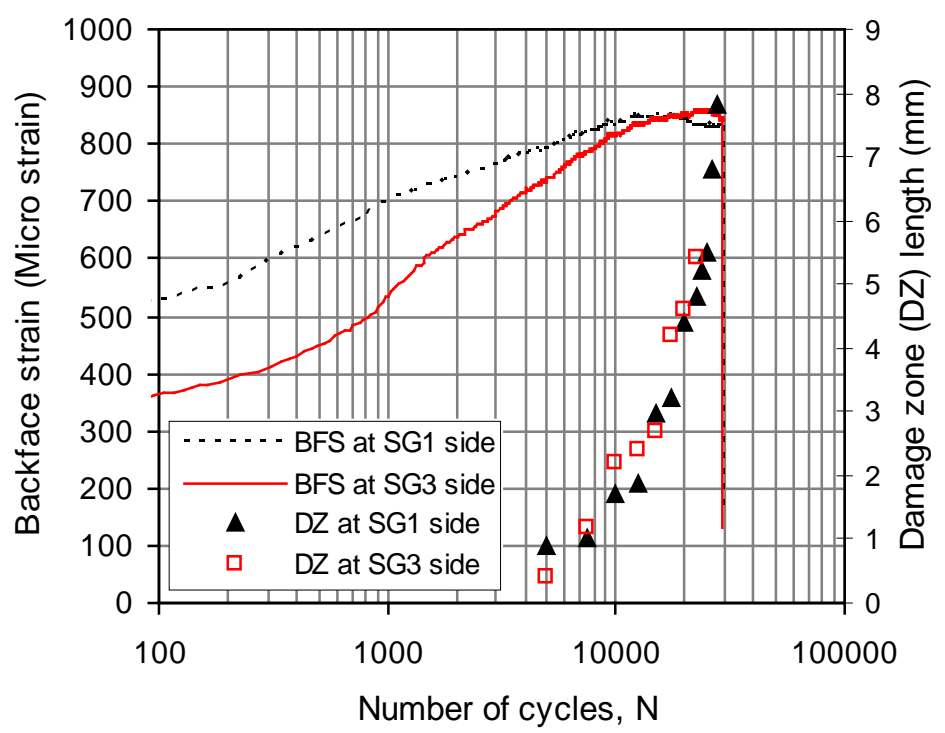

Fig. 4 The variation of backface strain with number of cycles for an aged MSLJ (wet-1y) due to fatigue loading at a load level of $50 \%$. 


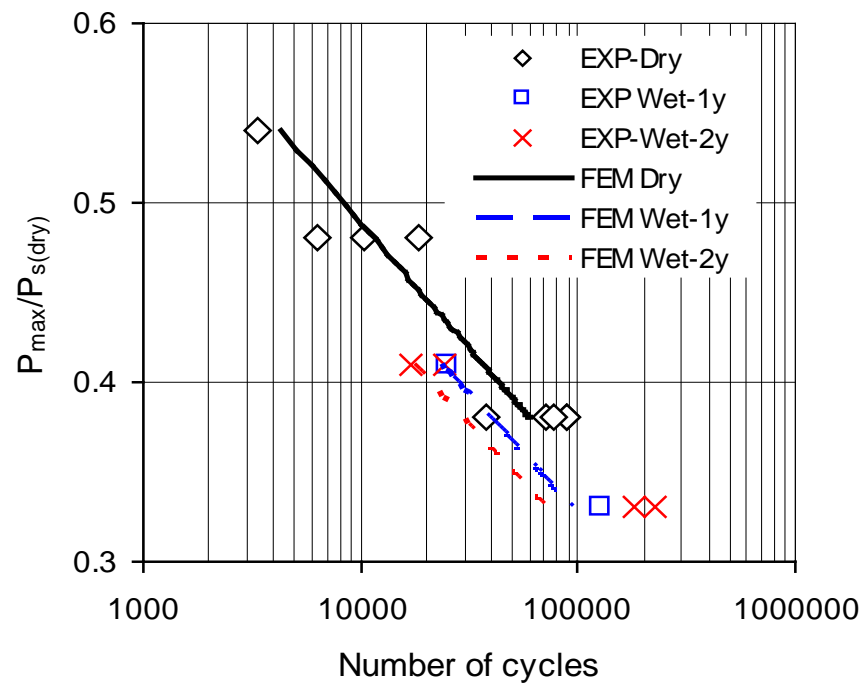

Fig. 5 Fatigue life of doublers loaded in bending in dry and wet conditions. The load level is normalised by the unaged static strength.
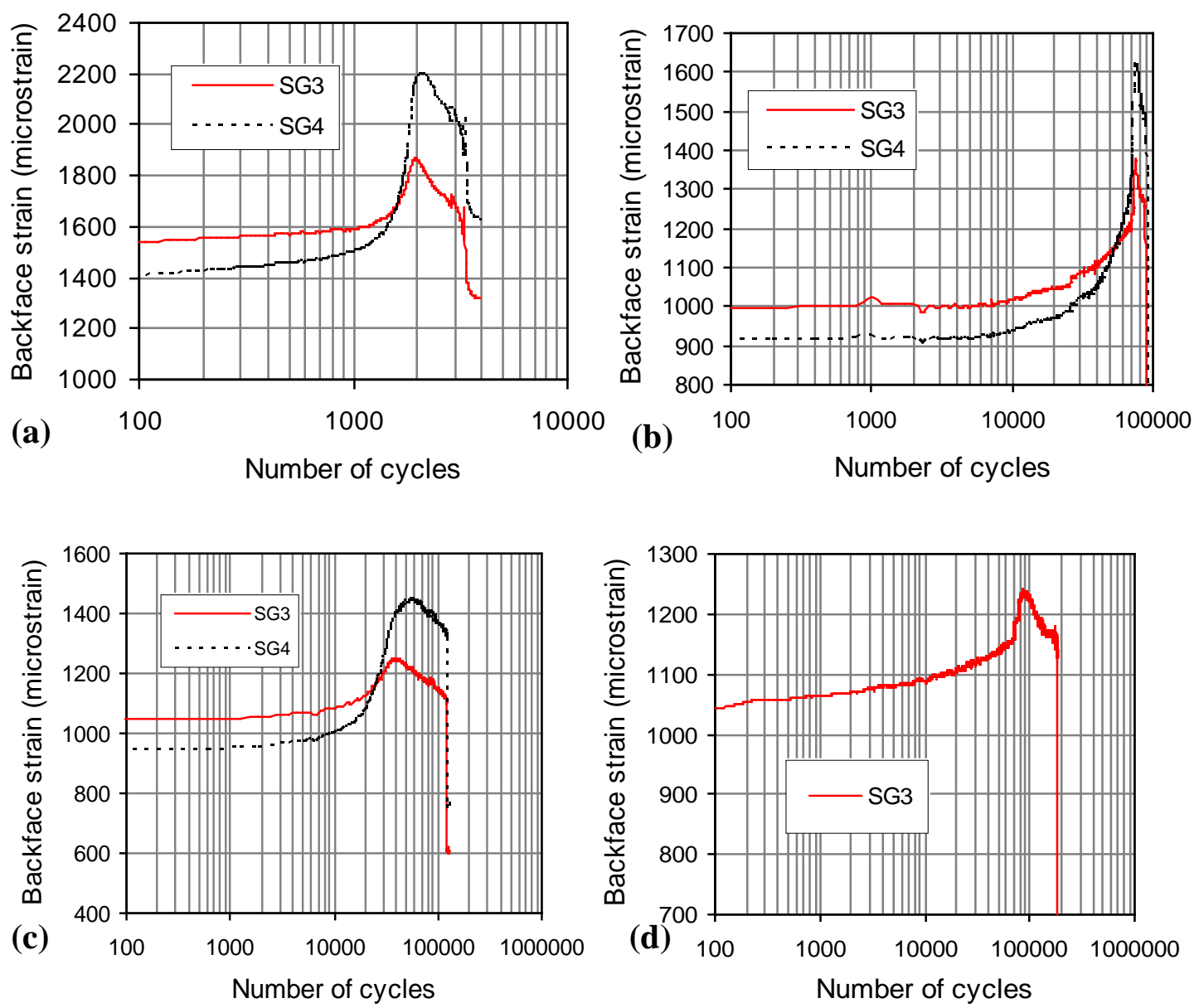

Fig. 6 Backface strain versus number of cycles of doublers in bending in (a) dry-1 (load level of 0.53), (b) dry-2 (load level of 0.38), (c) wet-1y (load level of 0.4), (d) wet-2y (load level of 0.4). 

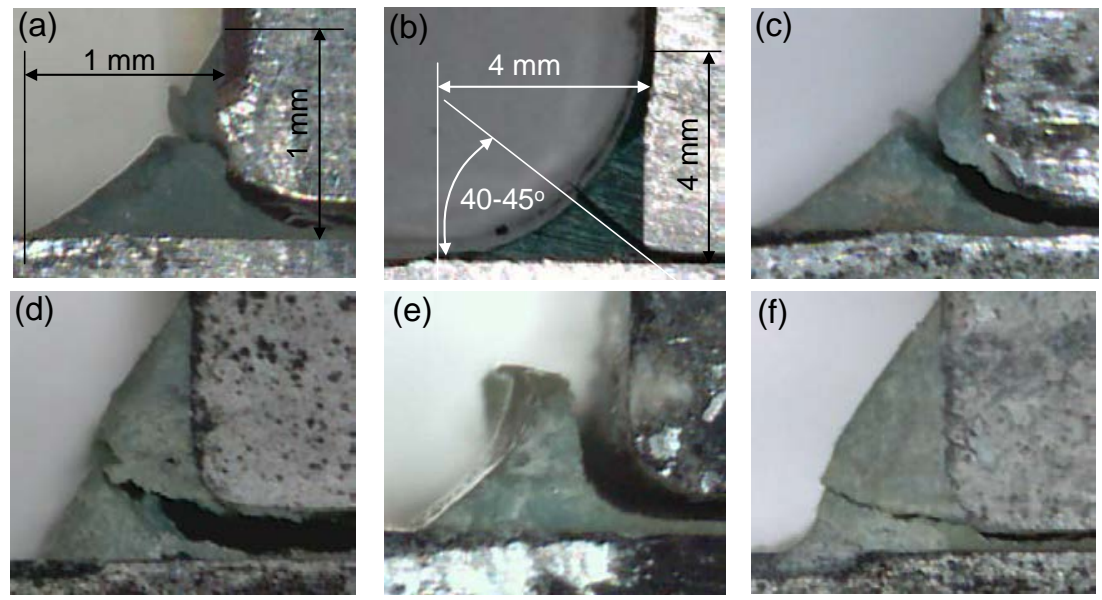

Fig.7 The fatigue failure in the fillet in LDB, (a) dry-1 (load level of 0.53), (b) dry-2 (load level of 0.38), (c) wet-1y (load level of 0.5), (d) wet-2y (load level of 0.5) (e) wet-1y (load level of 0.4), (f) wet-2y (load level of 0.4).
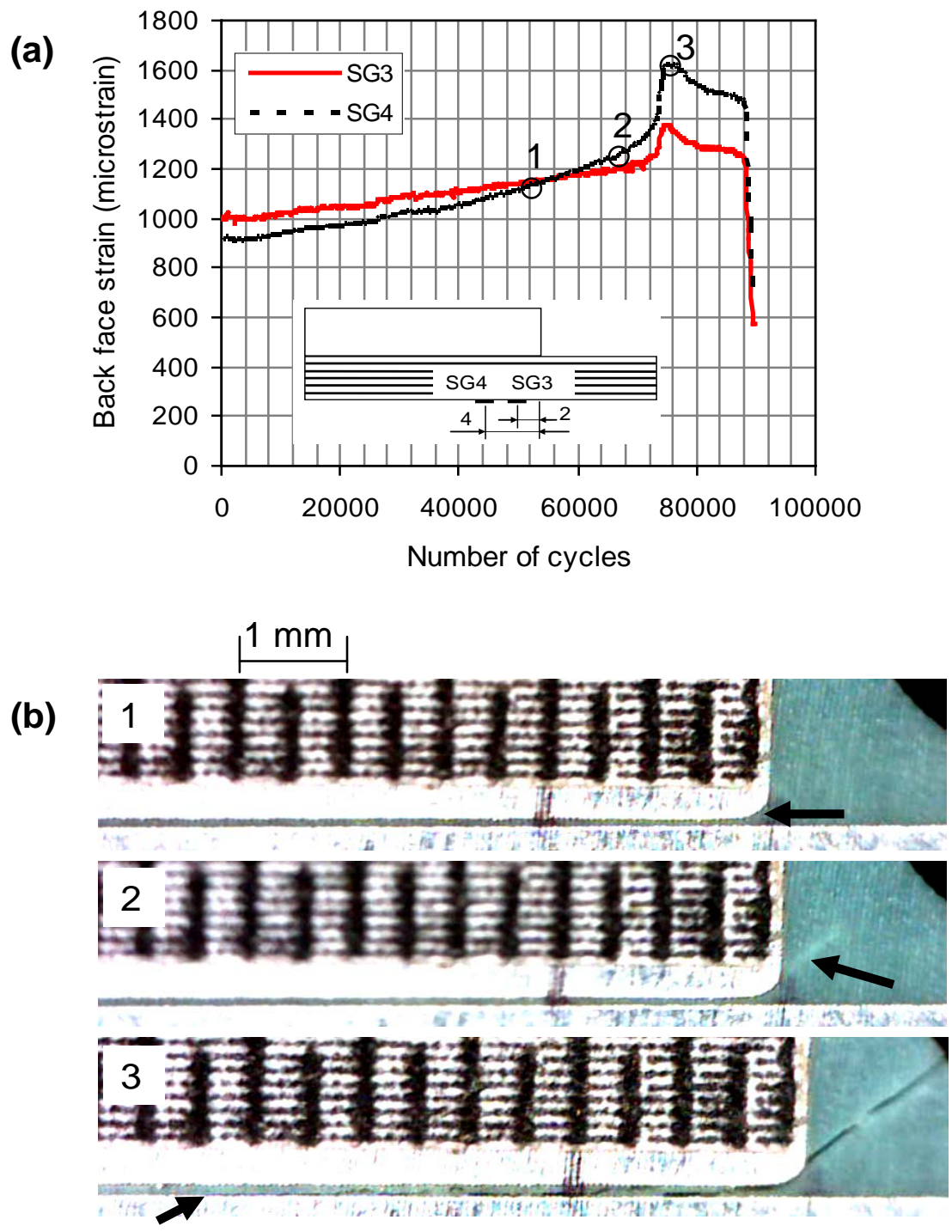

Fig. 8 The fatigue failure process of LDB (dry at load level of 0.38). (a) Backface strain history (b) Images of failure. 


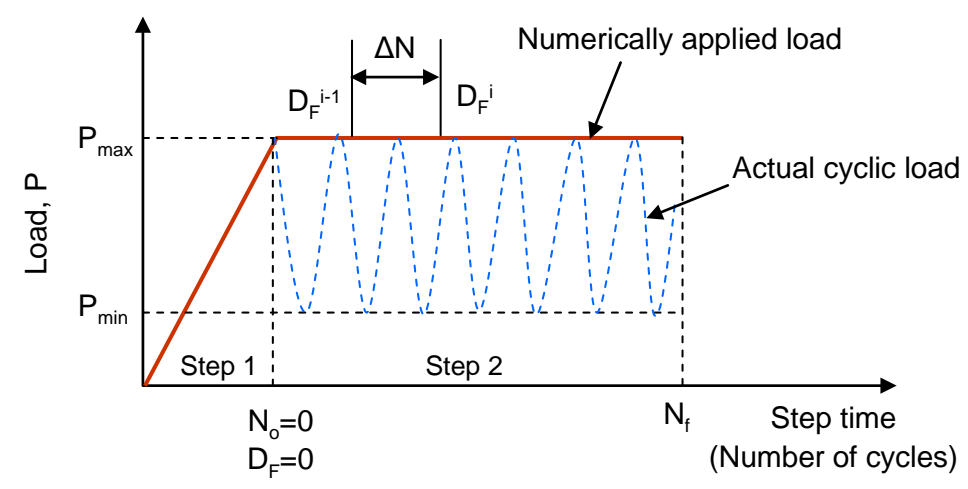

Fig. 9 Modelling approach of fatigue loading.

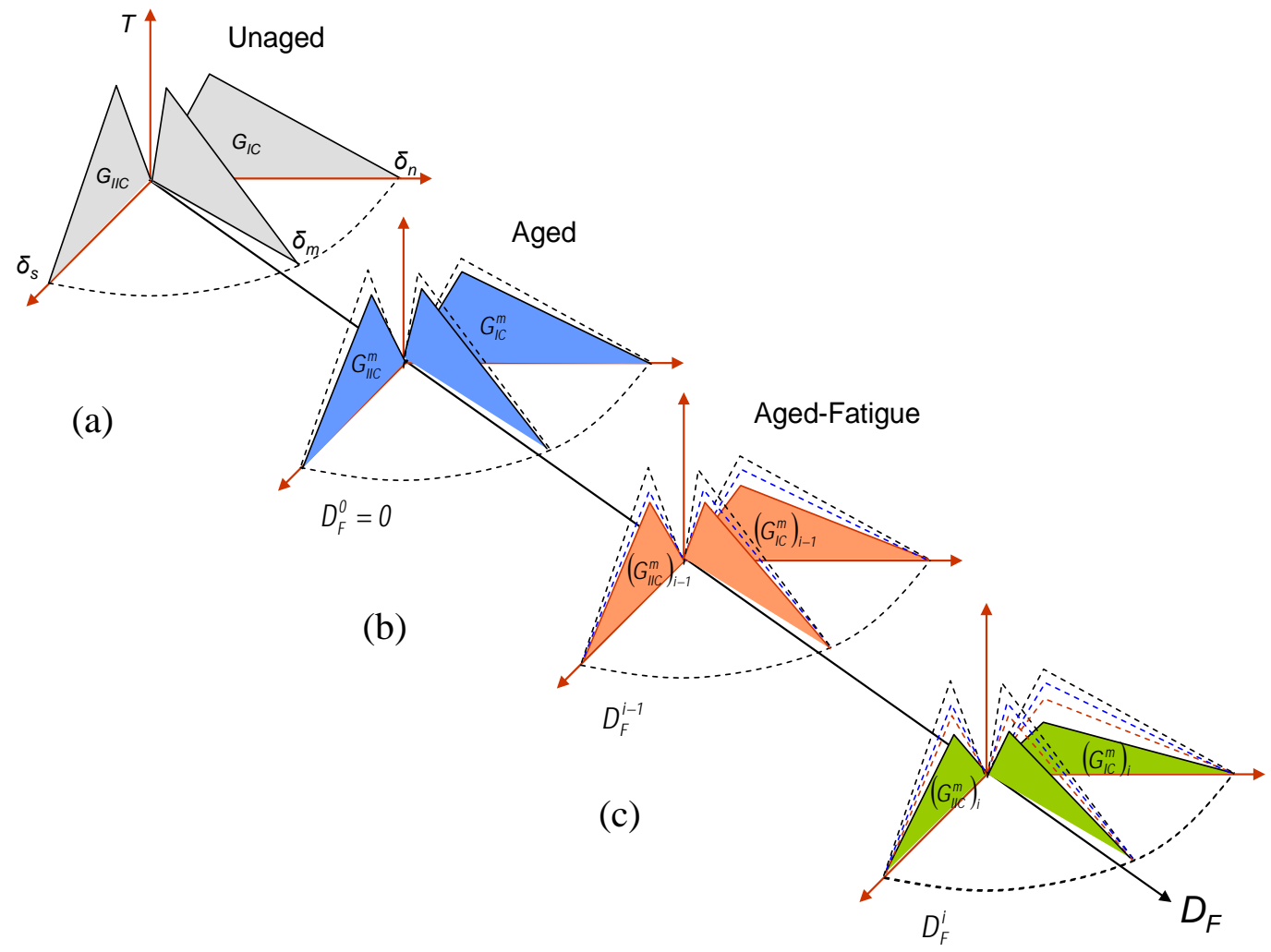

Fig. 10 The schematic of moisture and fatigue degradation of cohesive zone.

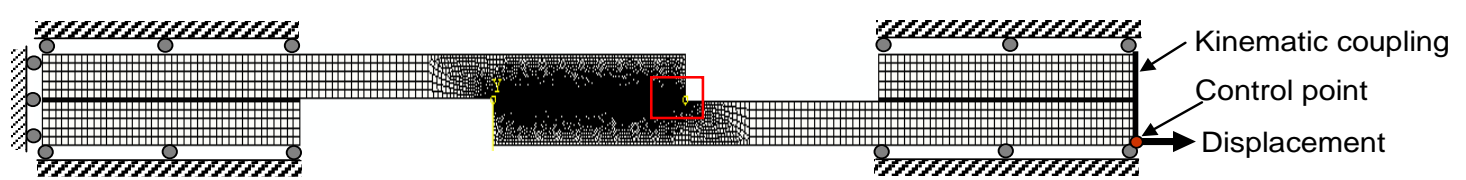




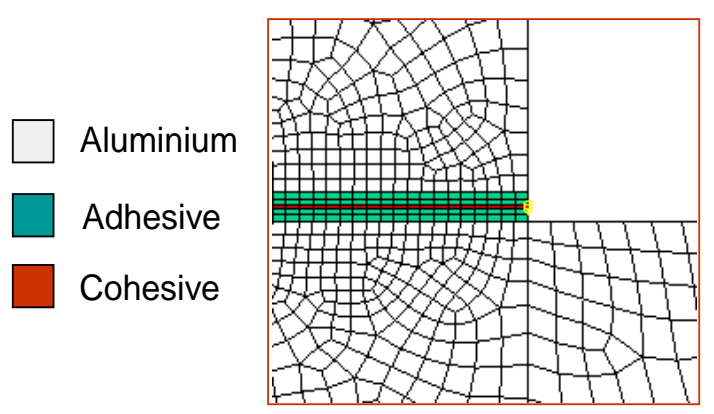

Fig. 11 The boundary condition and mesh of MSLJ.

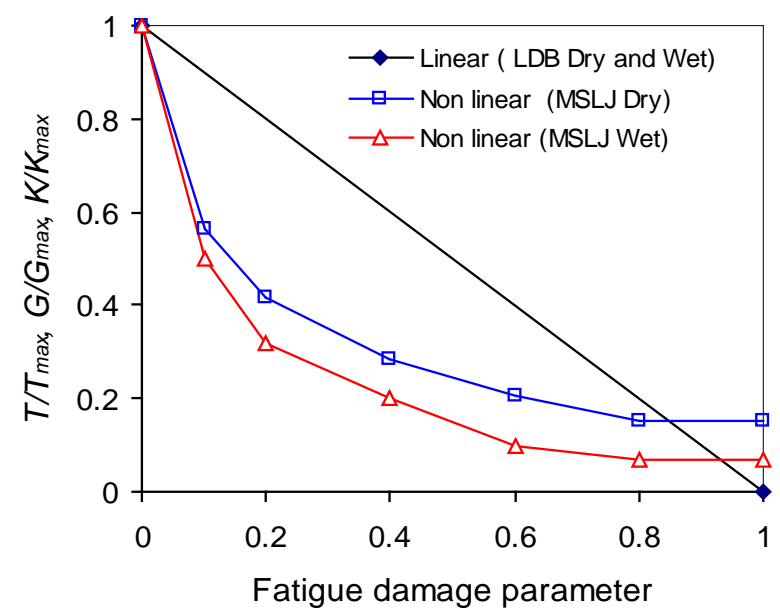

Fig.12 Fatigue degradation of the cohesive zone parameters.

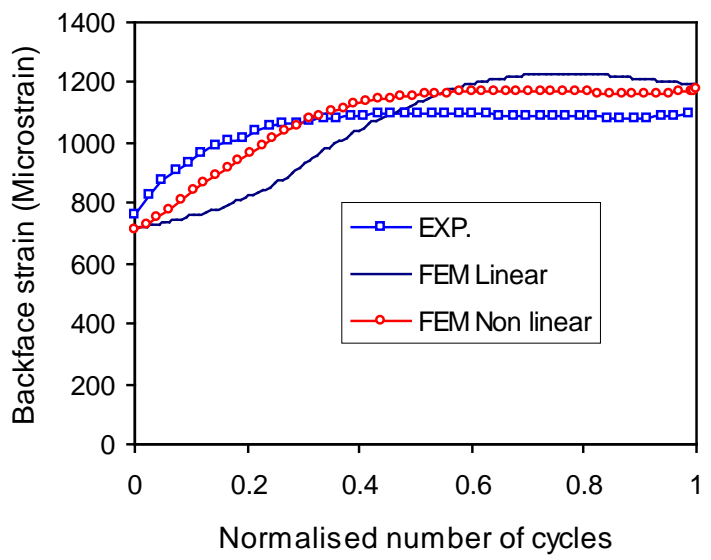

(a)

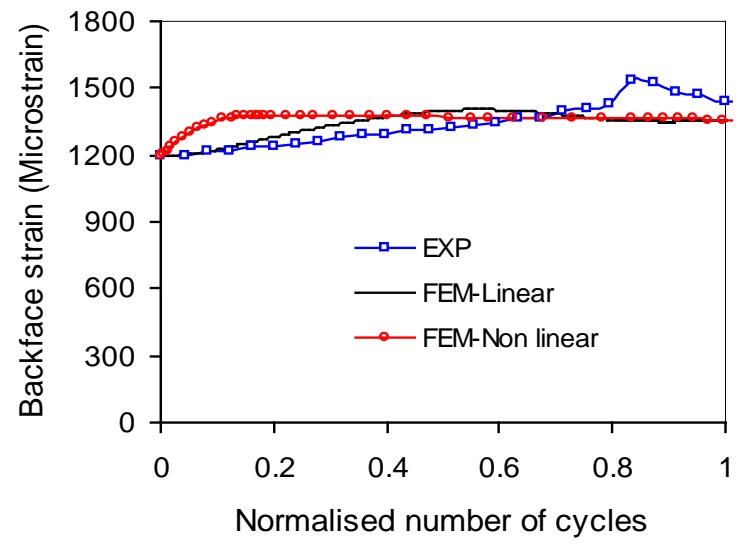

(b)

Fig.13 Predicted and experimental backface strains in unaged (a) MSLJ, (b) LDB. 


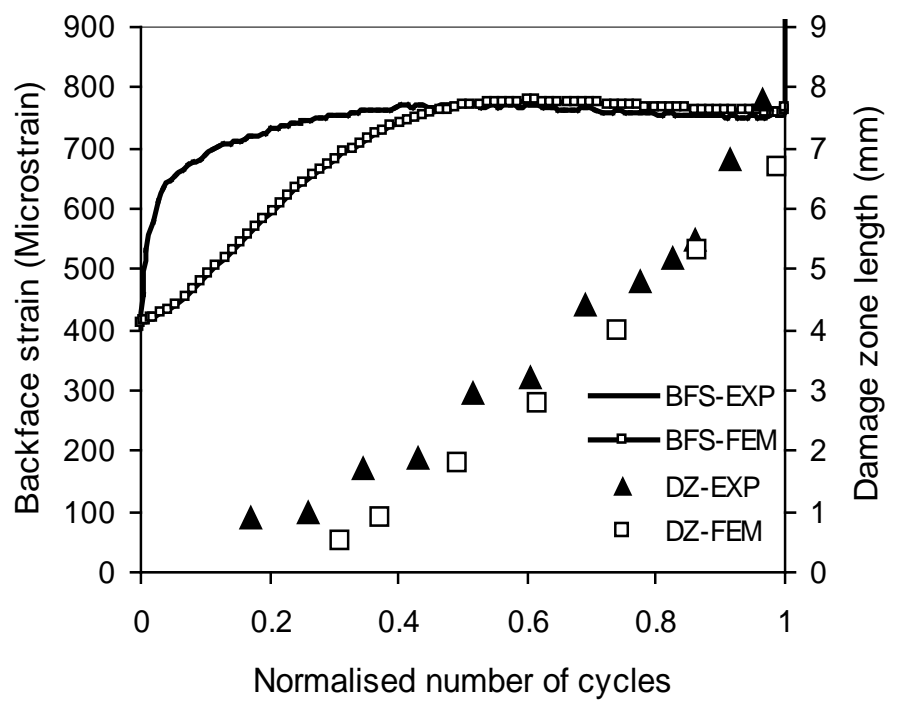

Fig. 14 The predicted backface strain (BFS) and damage zone (DZ) length of aged (wet-1y) MSLJ at load level $\left(\mathrm{P}_{\max } / \mathrm{P}_{\mathrm{s}(\text { wet-1y) }}\right)$ of $50 \%$.

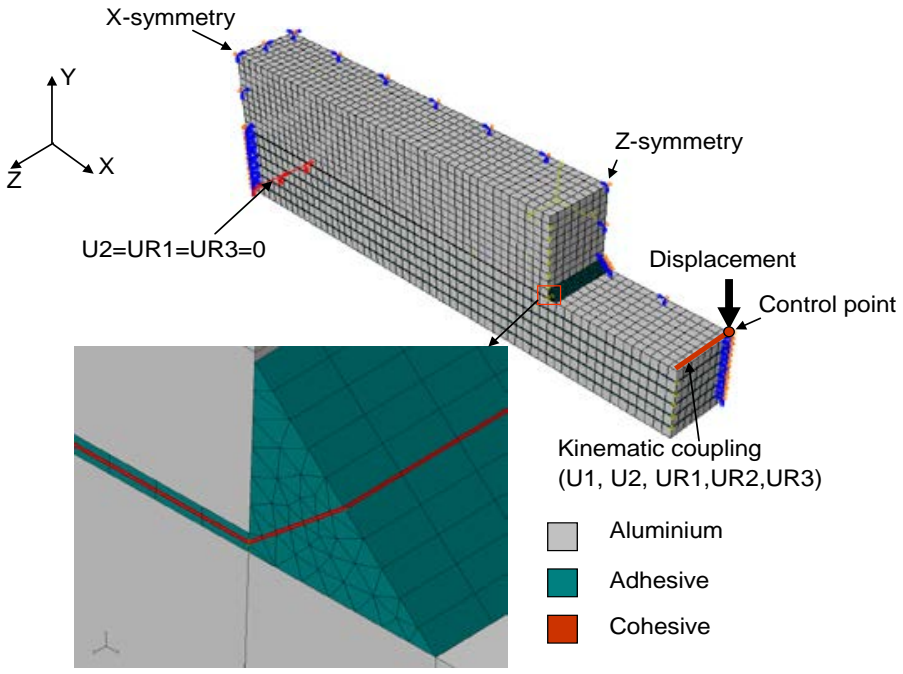

Fig. 15 FE boundary condition and meshing of LDB 


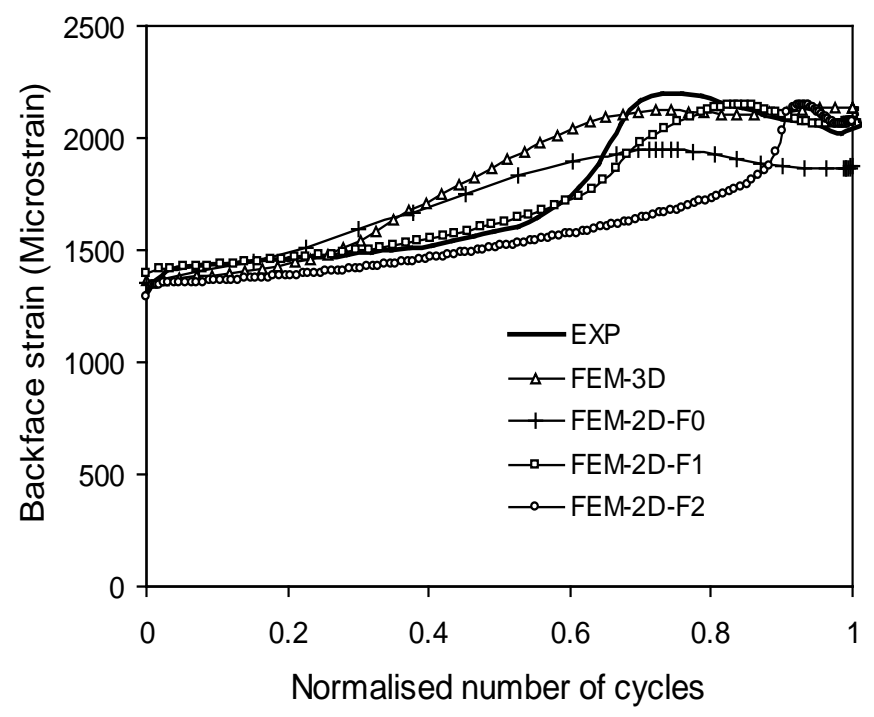

Fig. 16 The predicted backface strain of LDB in dry condition

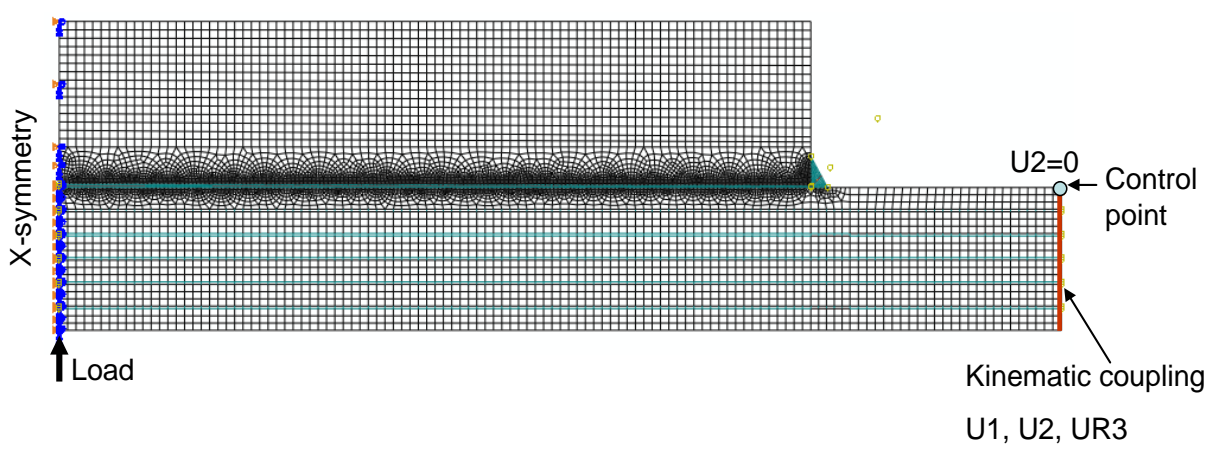

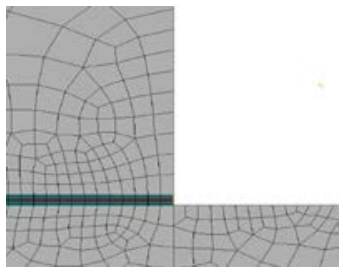

(a)

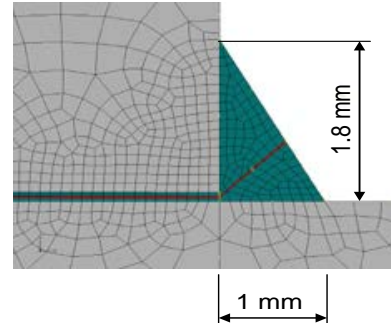

(b)

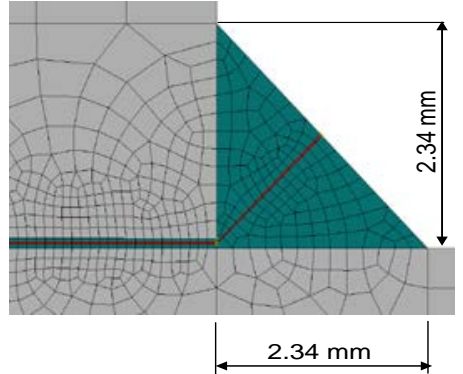

(c)

Fig.17 The fillet in FE 2D model (a) without fillet (F0), (b) small fillet (F1), (c) big fillet (F2). 


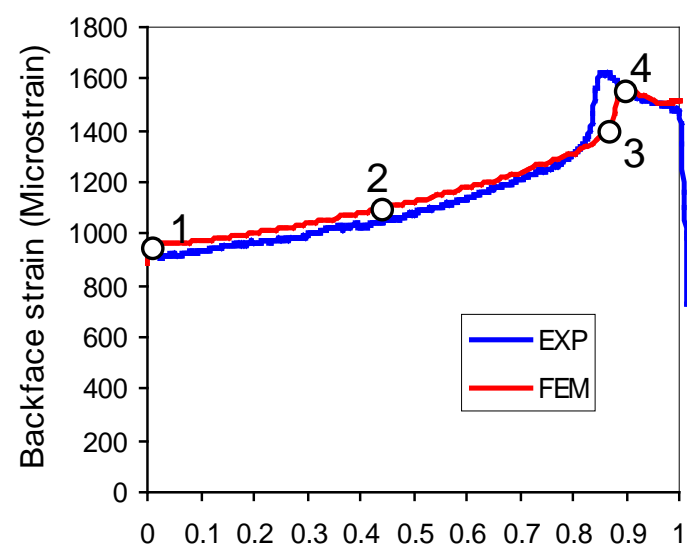

Normalised number of cycles, N/Nf

(a)

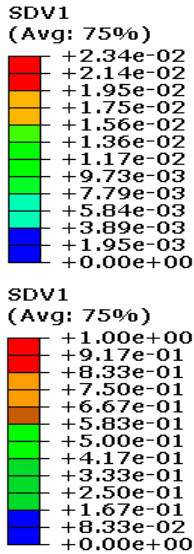

(1) SDV1 $75 \%$ )

(3)
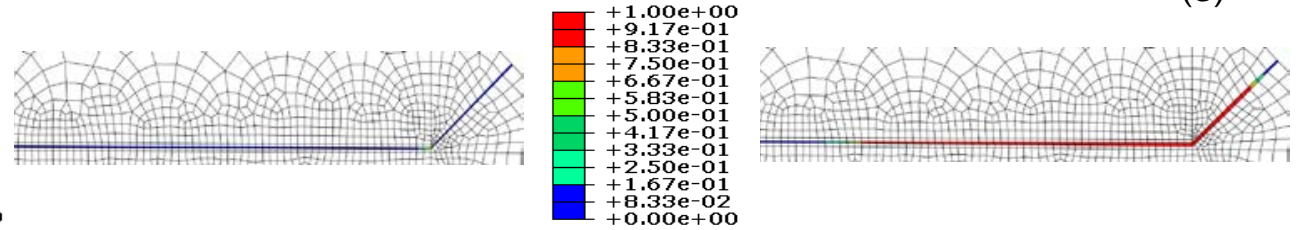

(2) SDV1

vg: 75\%)

(4)
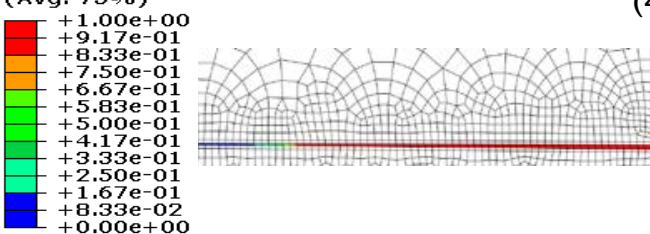

(b)

Fig. 18 (a) Backface strain vs. with the normalised number of cycles of LDB at load level $40 \%$ in dry condition, (b) The contour plot of fatigue damage. 